\title{
SYNTHESIS OF ACTIVE SCREENING SYSTEM OF MAGNETIC FIELD OF HIGH VOLTAGE POWER LINES OF DIFFERENT DESIGN TAKING INTO ACCOUNT SPATIAL AND TEMPORAL DISTRIBUTION OF MAGNETIC FIELD
}

Purpose. Analyze the spatial and temporal distribution of the magnetic field of high voltage power lines with different design
allowing and development of recommendations for the design of active screening systems by magnetic field of high voltage power
lines. Methodology. Analysis of the spatial and temporal distribution of the magnetic field of high voltage power lines of different
design allowing is made on the basis of Maxwell's equations solutions in the quasi-stationary approximation. Determination of
the number, configuration, spatial arrangement and the compensation coil currents is formulated in the form of multiobjective
optimization problem that is solved by multi-agent multiswarm stochastic optimization based on Pareto optimal solutions. Results
of active screening system for the synthesis of various types of transmission lines with different numbers of windings controlled.
The possibility of a significant reduction in the level of the flux density of the magnetic field source within a given region of
space. Originality. For the first time an analysis of the spatial and temporal distribution of the magnetic field of power lines with
different types and based on findings developed recommendations for the design of active screening system by magnetic field of
high voltage power lines. Practical value. Practical recommendations on reasonable choice of the number and spatial
arrangement of compensating windings of active screening system by magnetic field of high voltage power lines of different
design allowing for the spatial and temporal distribution of the magnetic field. Results of active screening system synthesis of the
magnetic field of industrial frequency generated by single-circuit $110 \mathrm{kV}$ high voltage power lines with the supports have $330-1 T$
"triangle» rotating magnetic field with full polarization in a residential five-storey building, located near the power lines. The
system contains three compensating coil and reduces the level of induction of the magnetic field source to the sanitary standards
of $0.5 \mu$ in almost of all the house space. References 8 , figures 5 . Key words: high voltage power lines, spatial and temporal distril active screening system.

Проведен анализ пространственно-временного распределения техногенного магнитного поля, создаваемого различными воздушными линиями электропередачи (ВЛ ЛЭП) внутри заданной области пространства. Приведены рекомендации по проектированию систем активного экранирования магнитного поля ЛЭП. Приведены результаты синтеза системы активного экранирования магнитного поля, создаваемого одноцепной ЛЭП ВЛ 110 кВ с опорой типа «треугольник» вращающегося магнитного поля с полной поляризацией в жилом пятиэтажном доме, расположенном вблизи ЛЭП. Система содержит три компенсационные обмотки и позволяет снизить уровень индукции исходного магнитного поля до санитарных норм практически во всем рассматриваемом пространстве жсилого дома. Эффективность системы активного экранирования составляет около 8. Библ. 8, рис. 5.

Ключевые слова: воздушные линии электропередачи, пространственно-временное распределение магнитного поля промышленной частоты, система активного экранирования.

Introduction. The most dangerous source of mancaused magnetic field (MF) of the power frequency for the population is high voltage power lines (PL) [2]. Without taking special measures, they create an intensive $\mathrm{MF}$ which has carcinogenic properties at distances up to $100 \mathrm{~m}$ from the PL. Therefore, sanitary norms [3] are tightened in the world according to the maximum permissible level of the flux density of the magnetic field of $50-60 \mathrm{~Hz}$ (less than $1 \mu \mathrm{T}$ ) and intensive work is carried out to provide them for the population. At present, strict sanitary norms for the flux density of MF $(0.5 \mu \mathrm{T})$ are also introduced in the normative documents of the Ministry of Energy of Ukraine [7]. However, at the moment in Ukraine these norms are universally exceeded which poses a threat to the health of millions of people who live closer than $100 \mathrm{~m}$ from high voltage PL.

Problem definition. The complex experimental investigations of the operating aerial PL 10-330 kV carried out at the Institute of Technical Problems of Magnetism of the NAS of Ukraine showed [8] that their $\mathrm{MF}$ is 3-5 times higher than the normative level at the border of the previously formed sanitary zones by the electric field.

This situation requires urgent measures to reduce the existing power lines within the city limits of Ukraine by
3-5 times. A similar situation is typical for most of the industrialized countries of the world, but in these countries, technologies for normalizing the MF of the operating PL have been created and widely used [1-5].

The most effective technology is the re-construction of the power line by removing it to a safe distance from residential buildings, or by replacing an overhead power line with a cable line. However, such a reconstruction requires enormous material resources. Therefore, less costly methods for shielding MF of operating PL are more acceptable for Ukraine, of which the necessary active methods are provided by methods of active contour screening of the magnetic field.

The technology of active contour screening of the existing PL is developed and used in developed countries for more than 10 years, for example in the USA and Israel [1-5]. In Ukraine, at the present time, both this technology and the scientific foundations of its creation are lacking. This does not allow relatively inexpensive methods to protect the population from the technogenic MF of the power frequency created by the power line. Therefore, the creation of scientific foundations of the domestic technology of active screening of industrial frequency MF in homes to a safe level is an actual scientific and technical problem. 
The goal of the work is analysis of spatial and temporal distribution of MF PL of different design and development of recommendations for the design of active screening systems for high voltage PL.

Analysis of the spatial and temporal distribution of the magnetic field of the PL of various design. As the first example we consider a PL with a support ЛБ 330-3, in which current conductors are located in the horizontal plane, the photograph of which is shown in Fig. 1,a. The layout of the current conductors and the points at which the hodographs of the MF will be considered are shown in Fig. 1,b, and Fig. 1,c shows the hodographs of the MF vectors in the three points under consideration.

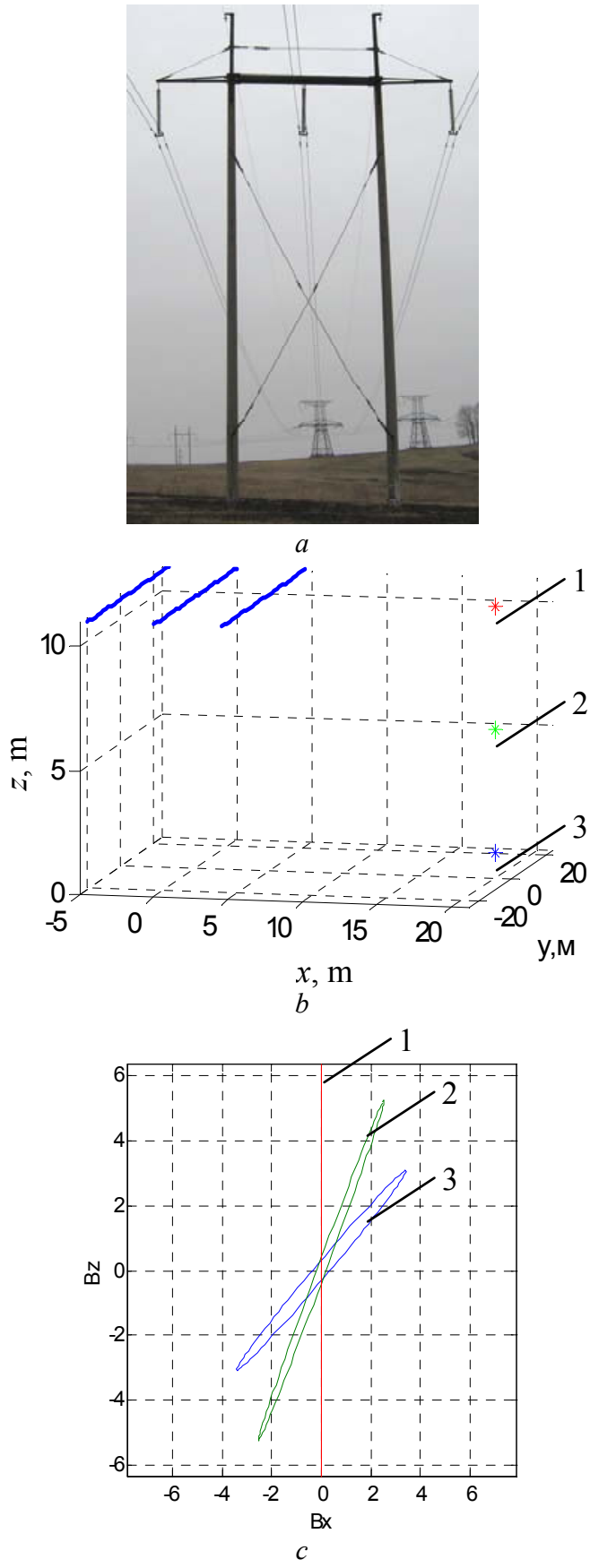

Fig. 1. Single-circuit PL with support ЛБ $330-3$

As can be seen from Fig. 1, the hodographs of the MF represent strongly elongated ellipses, and at point 1 the coefficient of ellipticity (the ratio of the smaller semiaxis of the ellipse to the larger semiaxis) is generally zero, so that the hodograph of the vector of the MF is stretched into a vertical line.

As the second example, we consider a single-circuit PL with a support $\mathrm{Y} 330$ in which current conductors are located one below the other in a vertical plane, as shown in Fig. 2,a. The layout of the current conductors and the points in which the hodographs of the MP will be considered are shown in Fig. 2,b, and Fig. 2,c show the hodographs of the MF vector at the points under consideration.

As can be seen from Fig. 2, the hodographs of the MF of this PL also represent strongly elongated ellipses, and at point 1 the major axis of the ellipse is in the horizontal plane. In general, the hodographs of this PL are deployed with respect to the travel time curves shown in Fig. $1, c$, by the angle $\pi / 2$.

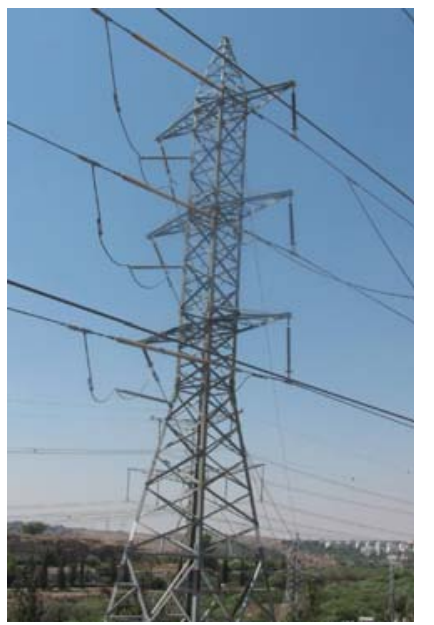

$a$

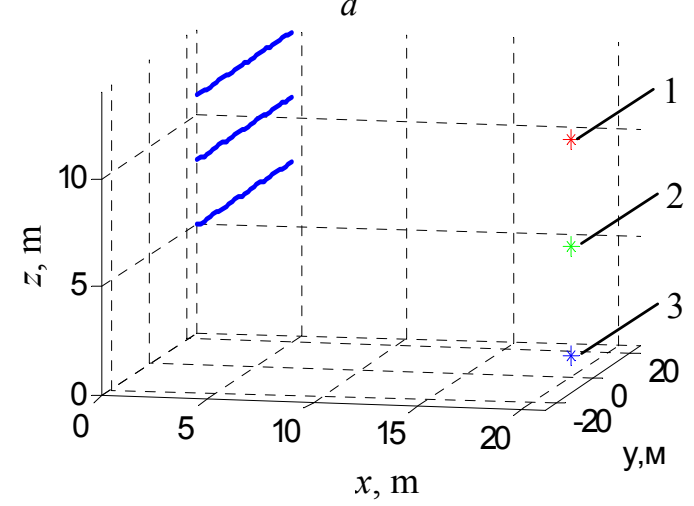

$b$

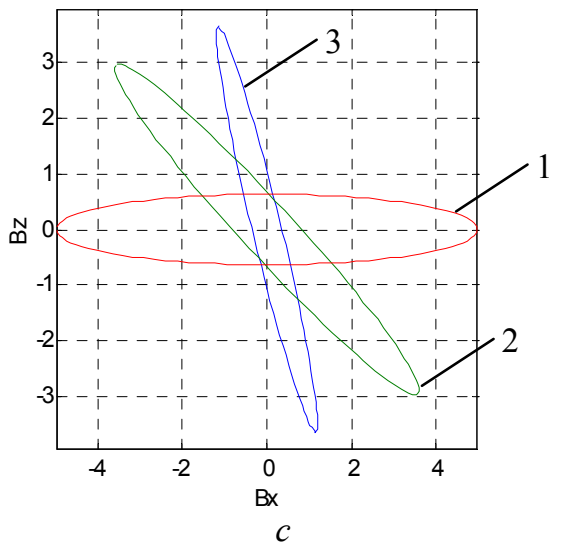

Fig. 2. Single-circuit PL with support Y 330 
As the third example, let us consider the most widespread version of a double-circuit PL with supports of type Y 330-2 of the «barrel» type, in which the current conductors are arranged in a form resembling a barrel, whose photograph is shown in Fig. 3, $a$.

The layout of the current conductors and the points at which the hodographs of the MF will be considered are shown in Fig. 3,b, and the hodographs of the MF vector at the three points under consideration are shown in Fig. 3,c. As can be seen from Fig. 3, the hodographs of this MF represent less elongated ellipses, in comparison with the hodographs of the MP, produced by the PL with supports: ЛБ $330-3$ and $\mathrm{Y}$ 330, which are shown in Fig. 1,c and Fig. 2,c, respectively.

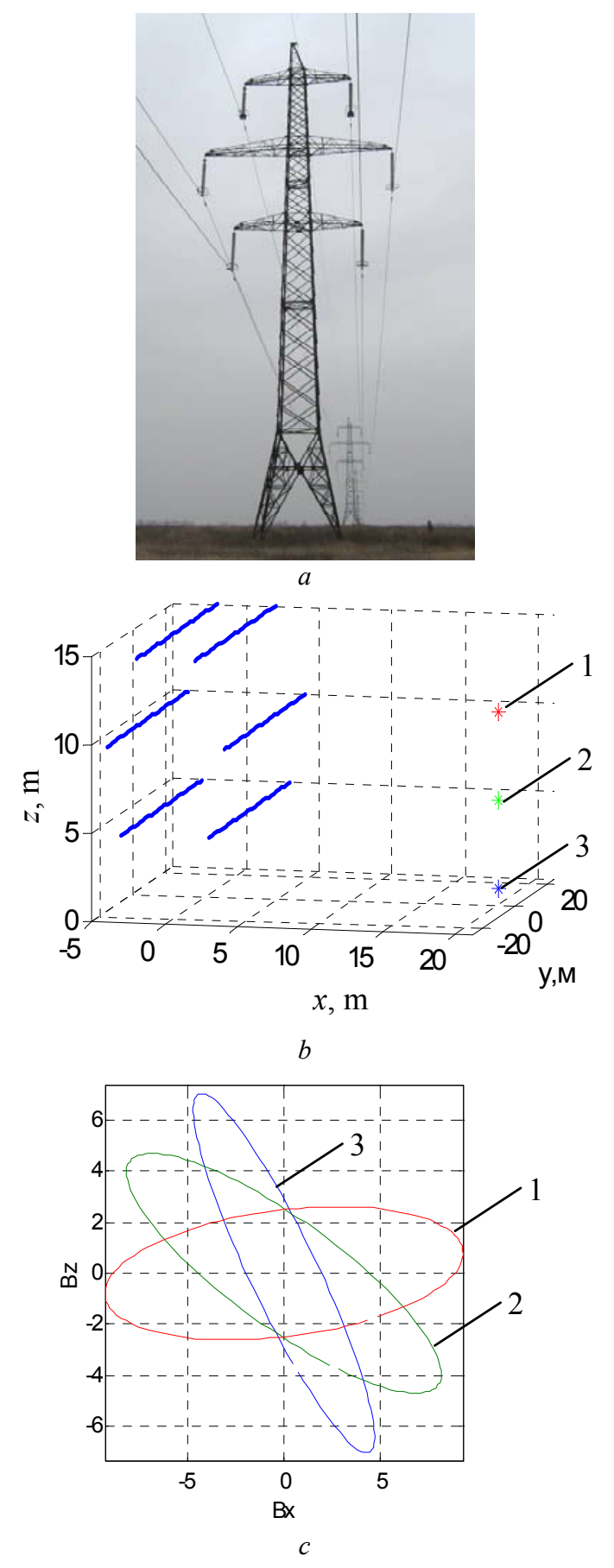

Fig. 3. Double-circuit PL with supports Y $330-2$ type «barrel»
As the fourth example, let us consider the most widespread version of a single-circuit PL with the $\mathrm{Y} 330$ - 1T support of the «triangle» type, the photograph of which is shown in Fig. 4, $a$, and Fig. 4, $b$ shows the scheme of the arrangement of the current conductors and the points at which the hodographs of the MF will be considered, and Fig. 4,c shows the hodographs of the MF vector themselves. As can be seen from Fig. 4, the hodographs of this magnetic field are close to a circle, so that the coefficients of the ellipticity of the soil are equal to unity, and hence this MF is strongly polarized.

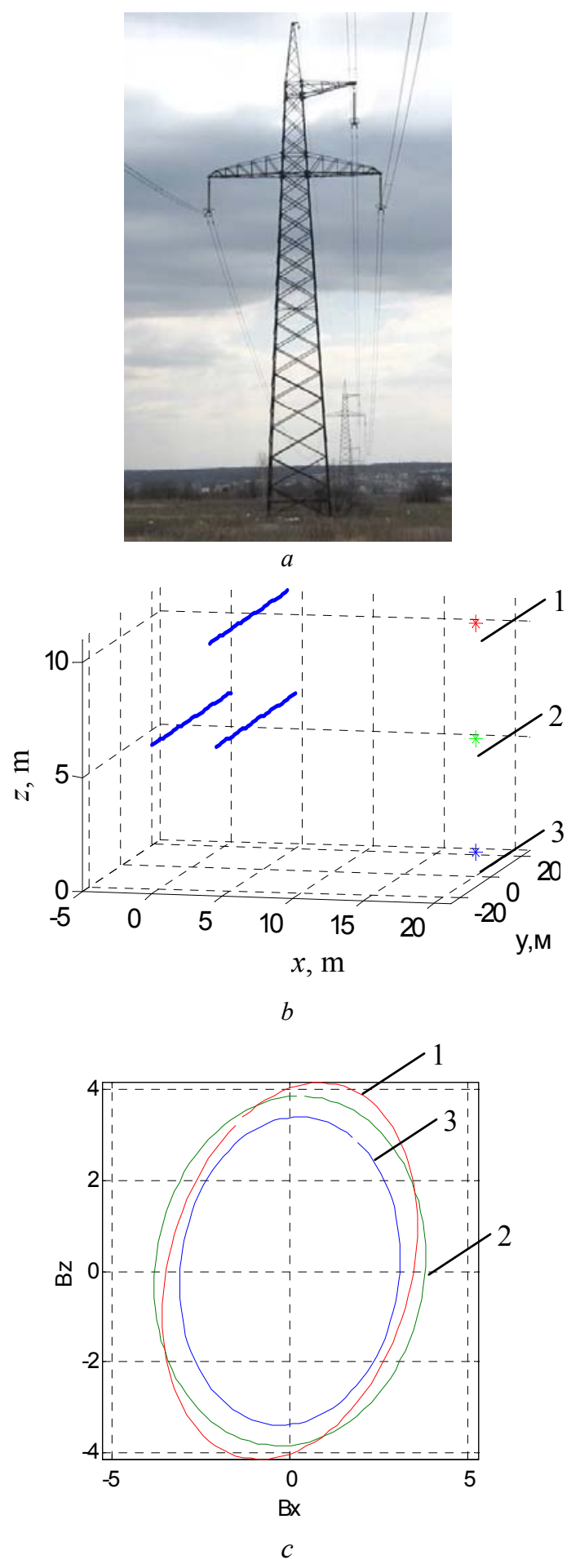

Fig. 4. Single-circuit PL with support У $330-1 \mathrm{~T}$ type «triangle» 
The principle of designing an active screening system. The essence of the method of active screening of PL consists in the formation of compensating windings with such a spatial and temporal structure whose superposition with a power line in the protection zone is minimized to the level of sanitary standards. The method is realized with the help of an active screening system which consists of compensating windings, by means of which a compensating magnetic field is formed. The currents in the compensation windings are automatically generated by a certain algorithm in the function of the signal from the MF sensors installed in the protection zone. The system contains a current source that receives energy from an external source.

When using only one compensation winding in the active shielding system, it is possible to create a compensating MF, the flux density vector of which is orthogonal to the winding plane and does not change its position with time. Therefore, using such a system, it is possible to compensate for the semimajor axis of the ellipse of the hodograph of the induction vector of the magnetic field and to obtain a sufficiently high screening efficiency for a weakly polarized MF. Such systems can be recommended to compensate for the weakly polarized magnetic field produced by the PL with supports ЛБ 330 -3 , Y 330 and Y $330-2$ «barrel». It is for PL with these types of supports that the world's active screening system with one compensation winding is the most widely used $[1,2,4]$.

To compensate for the highly polarized magnetic field, a power line with $\mathrm{Y} 330$ - 1T «triangle» supports is required, at least two compensating windings are required.

The method of synthesis of effective closed systems of active screening of industrial frequency MF created by airPL in residential buildings was developed in [6]. The method is based on the solution of the multicriteria optimization problem in which the calculation of the vectors of the objective function and constraints is performed on the basis of the Maxwell equations in the quasi-stationary approximation, and the optimization problem is solved by the multi-stochastic stochastic multiagent optimization method based on Pareto optimal solutions.

Results of computer modeling. As an example, let's consider the synthesis of the active screening system of a single-circuit PL of $110 \mathrm{kV}$ «triangle» creating a rotating $\mathrm{MF}$ with full polarization in a residential fivestory house located near the power line, the scheme of which is shown in Fig. 5,a. At the PL current of 1000 A, the initial flux density of the MF in the space under consideration is $4 \mu \mathrm{T}$ which is 8 times higher than sanitary norms [7]. To compensate for this technogenic MF in the space under consideration, three compensation windings were required, the spatial arrangement of which is shown in Fig. 5,a. The estimated number of ampereturns of compensating windings is 177,195 and 199. The distribution of the resultant MF with the switched on active screening system is shown in Fig. 5,b. As can be seen from Fig. 5, with the help of the active screening system, it was possible to reduce the level of induction of the initial MF to sanitary standards in practically the entire considered space of the residential building. The efficiency of the active screening system is about 8 .
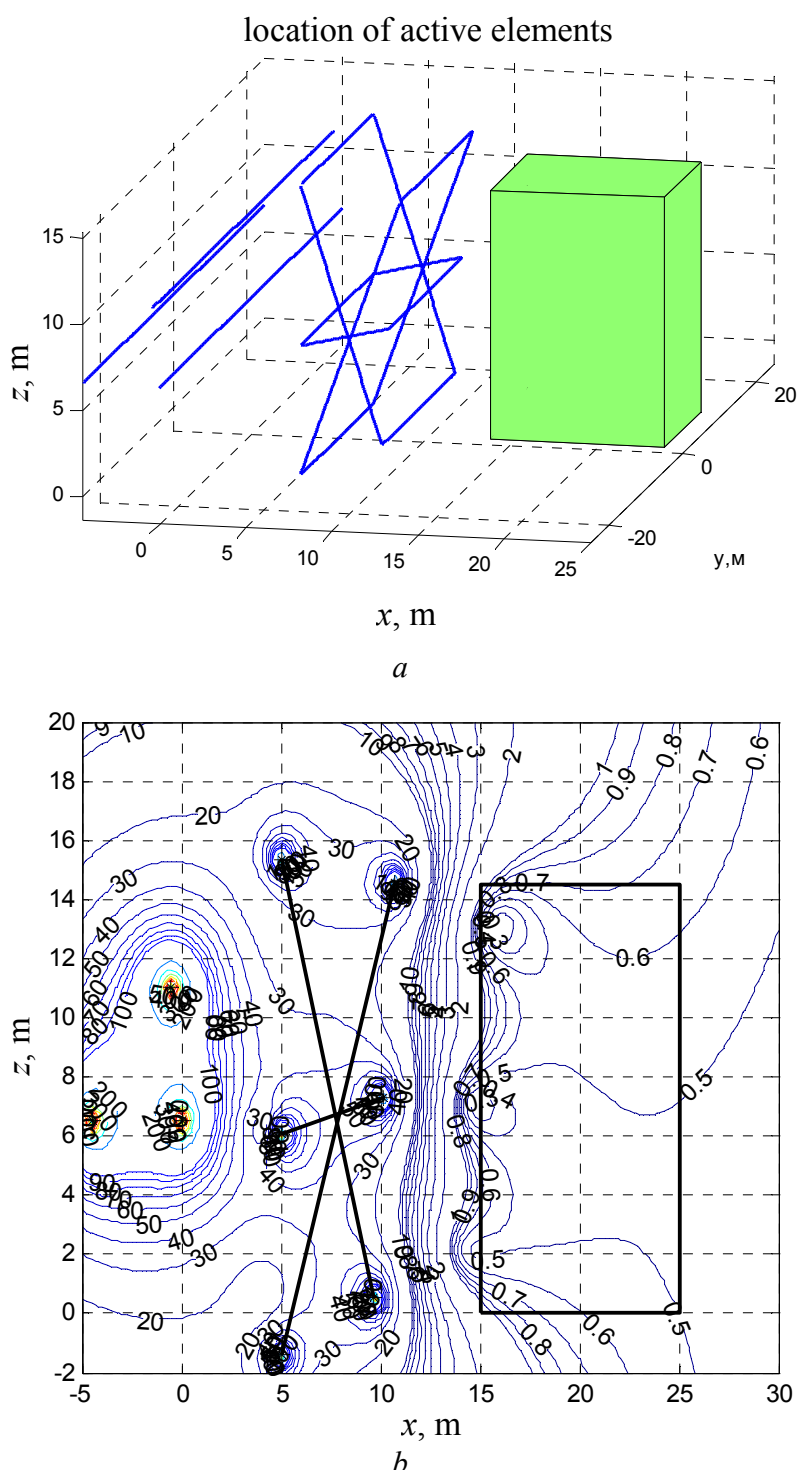

Fig. 5. The layout of PL, compensating windings and protected area $(a)$ and distribution of the total magnetic field with the switched on system of active shielding $(b)$

\section{Conclusions.}

The analysis of the spatial and temporal distribution of the MF produced by the PL of various designs with ЛБ 330 - 3, У 330, У $330-2$ «barrel» and Y $330-1 \mathrm{~T}$ «triangle» supports is carried out.

The recommendations on the design of compensating windings for active screening systems for high voltage PL are developed. The results of the synthesis of the active shielding system for the magnetic field of the industrial frequency, a single-circuit power line of $110 \mathrm{kV}$ with supports $\mathrm{y} 330$ - $1 \mathrm{~T}$ «triangle», rotating MF with full polarization in a residential fivestory house located near the power lines are presented.

The system contains three compensating windings and allows to reduce the level of induction of the initial MF to sanitary standards of $0.5 \mu \mathrm{T}$ in almost the entire considered space of the living house. The efficiency of the active screening system is about 8 . 


\section{REFERENCES}

1. Active Magnetic Shielding (Field Cancellation). Available at: http://www.emfservices.com/afcs.html (accessed 10 September 2012)

2. Beltran H., Fuster V., García M. Magnetic field reduction screening system for a magnetic field source used in industrial applications. 9 Congreso Hispano Luso de Ingeniería Eléctrica (9 CHLIE), Marbella (Málaga, Spain), 2005, pp. 84-99.

3. Ter Brake H.J.M., Huonker R., Rogalla H. New results in active noise compensation for magnetically shielded rooms. Measurement Science and Technology, 1993, Vol. 4, Issue 12, pp. 1370-1375. doi: 10.1088/0957-0233/4/12/010.

4. Celozzi S., Garzia F. Active shielding for power-frequency magnetic field reduction using genetic algorithms optimization. IEE Proceedings - Science, Measurement and Technology, 2004, Vol.151, no.1, pp. 2-7. doi: 10.1049/ip-smt:20040002

5. Shenkman A., Sonkin N., Kamensky V. Active protection from electromagnetic field hazards of a high voltage power line. HAIT Journal of Science and Engineering. Series B: Applied Sciences and Engineering, Vol. 2, Issues 1-2, pp. 254-265.

6. Kuznetsov B.I., Turenko A.N., Nikitina T.B., Voloshko A.V., Kolomiets V.V. Method of synthesis of closed-loop systems of active shielding magnetic field of power transmission lines. Tekhnichna elektrodynamika, 2016, no.4, pp. 8-10. (Rus). 7. Pravila ulashtuvannya electroustanovok. Vyd. 3, pererob. $i$ dop [Electrical Installation Regulations. 3rd edition, revised and enlarged]. Kyiv, Minpalyvenergo of Ukraine Publ., 2010. 736 p. (Ukr).

8. Rozov V.Yu., Grinchenko V.S., Pelevin D.Ye., Chunikhin K.V. Simulation of electromagnetic field in residential buildings located near overhead lines. Tekhnichna elektrodynamika, 2016, no.3, pp. 6-8. (Rus).

Received 15.09.2016

B.I. Kuznetsov ${ }^{1}$, Doctor of Technical Science, Professor,

T.B. Nikitina ${ }^{2}$, Doctor of Technical Science, Professor, A.V. Voloshko ${ }^{1}$, Candidate of Technical Science,

I.V. Bovdyj ${ }^{1}$, Candidate of Technical Science,

E.V.Vinichenko ${ }^{1}$, Candidate of Technical Science,

B.B. Kobilyanskiy ${ }^{1}$, Candidate of Technical Science, Associate

Professor,

${ }^{1}$ State Institution «Institute of Technical Problems of Magnetism of the NAS of Ukraine»,

19, Industrialna Str., Kharkiv, 61106, Ukraine, phone+38050 5766900, e-mail: bikuznetsov@mail.ru ${ }^{2}$ Kharkov National Automobile and Highway University, 25, Petrovskogo Str., Kharkov, 61002, Ukraine, e-mail: tatjana55555@gmail.com

How to cite this article:

Kuznetsov B.I., Nikitina T.B., Voloshko A.V., Bovdyj I.V., Vinichenko E.V., Kobilyanskiy B.B. Synthesis of active screening system of magnetic field of high voltage power lines of different design taking into account spatial and temporal distribution of magnetic field. Electrical engineering \& electromechanics, 2017, no.2, pp. 29-33. doi: 10.20998/2074-272X.2017.2.04. 